University of Nebraska - Lincoln

DigitalCommons@University of Nebraska - Lincoln

Recovery of pectic hydrocolloids and phenolics from huanglongbing related dropped citrus fruit

\author{
Randall G. Cameron \\ USDA-ARS, randall.cameron@ars.usda.gov \\ Hoa K. Chau \\ USDA-ARS, rose.chau@ars.usda.gov \\ Arland T. Hotchkiss \\ USDA-ARS, arland.hotchkiss@ars.usda.gov \\ John A. Manthey \\ USDA-ARS, Wilbur.Widmer@ars.usda.gov
}

Follow this and additional works at: https://digitalcommons.unl.edu/usdaarsfacpub

Cameron, Randall G.; Chau, Hoa K.; Hotchkiss, Arland T.; and Manthey, John A., "Recovery of pectic hydrocolloids and phenolics from huanglongbing related dropped citrus fruit" (2017). Publications from USDA-ARS / UNL Faculty. 1771.

https://digitalcommons.unl.edu/usdaarsfacpub/1771

This Article is brought to you for free and open access by the U.S. Department of Agriculture: Agricultural Research Service, Lincoln, Nebraska at DigitalCommons@University of Nebraska - Lincoln. It has been accepted for inclusion in Publications from USDA-ARS / UNL Faculty by an authorized administrator of DigitalCommons@University of Nebraska - Lincoln. 


\title{
Recovery of pectic hydrocolloids and phenolics from huanglongbing related dropped citrus fruit
}

\author{
Randall G Cameron, ${ }^{\mathrm{a}}{ }^{*}$ Hoa K Chau, ${ }^{\mathrm{b}}$ Arland T Hotchkiss ${ }^{\mathrm{b}}$ \\ and John A Manthey ${ }^{\mathrm{a}}$
}

\begin{abstract}
BACKGROUND: Citrus pre-harvest fruit drop, caused by huanglongbing infection, has increased dramatically concomitant with declining tree health and crop harvest size. This loss of harvestable fruit is damaging to both growers and juice processors. Recovering and converting this fruit to alternative value added products would benefit the citrus industry. Therefore, we have explored the potential of using this fruit as a feedstock in our newly developed pilot scale continuous steam explosion process.

RESULTS: Whole fruits were converted to steam-exploded biomass using a continuous pilot scale process. The sugar composition of raw fruit and steam-exploded biomass was determined. Recovered pectic hydrocolloids and phenolic compounds were characterized. Pectic hydrocolloids comprised $78 \mathrm{~g} \mathrm{~kg}^{-1}$ of the dry material in the dropped fruit. Following the steam explosion process almost all of the pectic hydrocolloids were recoverable with a water wash. They could be functionalized in situ or separated from the milieu. Additionally, approximately $40 \%$ of the polymethoxylated flavones, $10 \%$ of the flavanone glycosides, $85 \%$ of the limonoids and almost $100 \%$ of hydroxycinnamates were simultaneously recovered.
\end{abstract}

CONCLUSION: The continuous steam explosion of pre-harvest dropped citrus fruit provides an enhanced, environmentally friendly method for the release and recovery of valuable coproducts from wasted biomass.

Published 2017. This article is a U.S. Government work and is in the public domain in the USA.

Keywords: pectin; galacturonic acid; flavonoids; biomass; biorefinery; hydrocolloid

\section{INTRODUCTION}

The US Florida citrus industry is in dire straits. Harvests have been reduced by almost $75 \%$ since 2003 and are expected to fall further, with growers and juice processors both suffering. The cause is huanglongbing (HLB) disease, which results from a bacteria spread by a sucking insect. There is no known cure, only stop gap, temporary and often poorly performing fixes. Unfortunately, this disease causes pre-harvest fruit drop, ${ }^{1-3}$ drastically reducing yields, as well as increased rejects at processing plants. During the 2013-14 harvesting season, $31 \%$ of the early/mid-season fruit and $25 \%$ of the late-season crop dropped from the trees. We estimate that these dropped fruits had a combined total of approximately $22 \mathrm{Mkg}$ of pectic hydrocolloids (almost one-half of the annual world demand) and $5 \mathrm{Mkg}$ of bioflavonoids/related phenolics and $1.5 \times 10^{5} \mathrm{~kg}$ of the 'Green' solvent limonene, for which neither the grower, nor the processor currently recover any value. The use of this fruit to create these value-added products would benefit both growers and juice processors in this largely rural industry.

The elevated pre-harvest release of maturing citrus fruit from diseased trees (fruit drop) has had an extremely negative impact on citrus producers. The economic cost to growers of this dropped fruit has been estimated at almost US $\$ 150$ million. ${ }^{1}$ It is also important to the juice processors that crop yields remain sustainable to support the existing industry. As the amount of dropped fruit increases and harvestable crop forecasts continue to shrink, finding a use for dropped fruit becomes of growing importance.
A considerable effort has been made to utilize citrus juice processing wastes as a feedstock for bioconversion to ethanol. ${ }^{4-7}$ A major obstacle for this conversion that was been overcome is the presence of limonene in peel. Limonene is antimicrobial and inhibits fermentation processes. ${ }^{8}$ A second obstacle is the cost of hydrolytic enzymes needed for the conversion of complex polysaccharides to simple, fermentable sugars.

Fortunately for the citrus juice processing industry, valuable components other than sugars are present in the waste peel

\footnotetext{
Correspondence to: RG Cameron, United States Department of Agriculture, Agricultural Research Service, US Horticultural Research Laboratory, Citrus and Other Subtropical Products Research Unit, Fort Pierce, FL, USA.

E-mail: randall.cameron@ars.usda.gov
}

This article is a US Government work and is in the public domain in the USA. Mention of a trademark or proprietary product is for identification only and does not imply a guarantee or warranty of the product by the US Department of Agriculture. The US Department of Agriculture prohibits discrimination in all its programs and activities on the basis of race, color, national origin, gender, religion, age, disability, political beliefs, sexual orientation and marital or family status

a United States Department of Agriculture, Agricultural Research Service, US Horticultural Research Laboratory, Fort Pierce, FL, USA

b United States Department of Agriculture, Agricultural Research Service, Eastern Regional Research Center, Wyndmoor, PA, USA 
stream at concentrations sufficient to justify the development of enabling technologies for their recovery and utilization. We have focused on two of these components: pectic hydrocolloids and bioactive phenolics. Pectin is a complex polysaccharide composed of two dominant regions. The homogalacturonan region is a linear polymer composed predominantly of galacturonic acid. Charged and neutral domains found within the homogalacturonan regions are largely responsible for pectin functionality. ${ }^{9,10}$ The rhamnogalacturonan I region is a linear copolymer of galacturonic acid and rhamnose. ${ }^{11}$ The pectic sugars rhamnose, galactose and arabinose are found in this region. The galactose and arabinose occur as side branches off of rhamnose residues. Beyond its extensive functionality in food applications, ${ }^{12}$ pectin also is used in personal care $^{13}$ and pharmaceutical ${ }^{14}$ products. More recently, its bioactive properties have also received considerable attention. ${ }^{15}$ Pectin, as marketed for food and pharmaceutical purposes, is a very high valued hydrocolloid historically, ranging from US $\$ 6.00$ to $\$ 12.00$ per pound, which reflects its unique functionality. More recently, these prices have started to rise as a result of both increased demand and a shrinking supply of citrus peel.

Research has confirmed health benefits of citrus juice products, and suggests a direct involvement of peel flavonoid components. These health benefits provide a basis for a much larger use of these compounds as food supplements, although new discoveries are needed to reach their full potential because important gaps still exist in our understanding of their pharmacokinetics and modes of action. Bioactive phenolics or their human metabolites have been identified and have been shown to be powerful mediators of gene activation in inflammation and other chronic diseases in humans. ${ }^{16-18}$ Other studies highlight exciting new applications, and thus potentially new markets for the citrus phenolics, including applications relating to bone resorption in osteoporosis and rheumatoid arthritis ${ }^{19}$ and to Alzheimer's disease. In particular, nobiletin has been shown to improve memory deficits, to decrease the $\beta$-amyloid burden and plaques, and to influence a number of key biological enzyme and protein markers of Alzheimer's disease. ${ }^{20,21}$ Prices for nobiletin range from US $\$ 1-10 \mathrm{~g}^{-1}$ for a crude extract to US $\$ 130 \mathrm{~g}^{-1}$ for purified product.

Worldwide citrus processing waste was projected to be almost $4.2 \times 10^{9} \mathrm{~kg}$ (dry) for the 2013-2014 harvesting season, ${ }^{22}$ containing approximately $840 \mathrm{Mkg}$ of pectic hydrocolloids and $190 \mathrm{Mkg}$ of flavonoids and related phenolics. ${ }^{23}$ For the $2013-2014$ harvesting season in Florida, 41 million boxes of early/mid-season and 37 million boxes of late-season oranges were processed for juice. ${ }^{24}$ This many oranges would contain approximately $55 \mathrm{Mkg}$ of pectin and 12.5 Mkg of flavonoids and related phenolics. However, during the 2013-2014 harvesting season, Albrigo and Stover ${ }^{1}$ reported that $31 \%$ of the early and mid-season fruit and $25 \%$ of the late-season crop dropped from the trees. Based on the 2013-2014 Annual Processors Statistics Report ${ }^{24}$ concerning the number of boxes of early/mid and late season fruit harvested and the dropped fruit percentages reported by Albrigo and Stover, ${ }^{1}$ we estimate more than 18 million boxes of early/mid-season and 12 million boxes of late season fruit fell from the trees and went unused. Assuming $40.8 \mathrm{~kg}$ per box of which $44 \%$ would have become citrus processing waste with an $80 \%$ moisture content, ${ }^{25}$ this results in almost $66 \mathrm{Mkg}$ of early/mid-season citrus processing waste and $44 \mathrm{Mkg}$ of late-season citrus processing waste. Assuming a pectin content of $20 \%$ on a dry weight basis and $4.5 \%$ for flavonoids and other phenolics, we can estimate that these dropped fruit had a combined total of approximately $22 \mathrm{Mkg}$ of pectic hydrocolloids and $5 \mathrm{Mkg}$ of flavonoids and related phenolics for which neither the grower, nor the processor recovered any value.

To assess the potential of using dropped fruit as a feedstock in our pilot scale, continuous process for the release and recovery of pectic hydrocolloids and flavonoids and related phenolics, we collected dropped Citrus sinensis (L.) Osbeck var. 'Hamlin' fruit (DHF) and processed them through our steam explosion system. In addition to the sugar composition of raw and cooked fruit, we estimated the recovery of pectic hydrocolloids and flavonoids and related phenolics following a simple water wash of the cooked fruit. We characterized the macromolecular structural properties of molecular weight and degree of methyl esterification for the pectic hydrocolloids, which are two major determinants of pectin functionality, and performed tests of their functional properties. We also identified and quantified the various types of flavonoid and phenolic compounds recovered.

\section{MATERIALS AND METHODS \\ Collection of dropped fruit and steam explosion}

During December of 2014, $250 \mathrm{~kg}$ of dropped fruit was collected from three rows of 'Hamlin' trees located on the Picos Road farm of the US Horticultural Research Laboratory in Fort Pierce, FL. Fruit were water washed to remove debris and stored overnight at $4{ }^{\circ} \mathrm{C}$. The next day, the entire fruit was processed as described previously (Fig. 1). ${ }^{26}$ Briefly, washed fruits were fed into a hopper and then transferred into a tube using a high solids pump. A jet cooker was used to inject steam into the fruit stream. The fruit was held under pressure at approximately $4.46-4.80 \mathrm{MPa}\left(\sim 150^{\circ} \mathrm{C}\right)$ by pumping them through a hold tube of a length designed to maintain the desired temperature and pressure for 1-3 min. This pressurized cooked fruit was then vented into a flash tank at atmospheric pressure. The rapid depressurization serves to reduce particle size of the cooked fruit. The steam-exploded dropped 'Hamlin' fruit was pumped into resealable plastic bags and frozen at $-20^{\circ} \mathrm{C}$.

\section{Compositional analysis of raw and steam-exploded fruit}

Samples of raw and cooked fruit were enzymatically hydrolyzed as described previously to determine their carbohydrate composition. ${ }^{27}$ Contents of insoluble and soluble solids were determined by filtration and drying. ${ }^{28}$ Statistical analyses were performed using Excel 2013 (Microsoft Corp., Redmond, WA, USA).

\section{Extraction of pectic hydrocolloids from steam-exploded fruit}

Aliquots $(100 \mathrm{~g})$ of steam-exploded dropped 'Hamlin' fruit were thawed and resuspended in an equal volume $(\mathrm{w} / \mathrm{v})$ of deionized water containing chloramphenicol $\left(10 \mathrm{mg} \mathrm{mL}^{-1}\right)$ and cycloheximide $\left(5 \mathrm{mg} \mathrm{mL}^{-1}\right)$ to recover released pectic hydrocolloids and phenolic compounds. ${ }^{26}$ Three washes were performed. An aliquot of each wash was stored at $4{ }^{\circ} \mathrm{C}$ until assayed for sugar composition as described above. The first and second wash solution from separate replicates were pooled for phenolic analysis.

\section{Composition of extracted pectic hydrocolloids}

Pectic hydrocolloids in pooled wash supernatants were precipitated with acidified ethanol $\left(550 \mathrm{~mL} \mathrm{~L}^{-1}\right)$ overnight at $4{ }^{\circ} \mathrm{C}^{29}$ After centrifuging at $12000 \times g$ for $20 \mathrm{~min}$ at $20^{\circ} \mathrm{C}$, the pellets were washed with acidified ethanol and centrifuged as described above and then frozen in liquid nitrogen and lyophilized (FreeZone Freeze Dry System; Labconco, Kansas City, MO, USA). A portion of the freeze dried pellet was made to a $10 \mathrm{~g} \mathrm{~kg}^{-1}$ solution and 


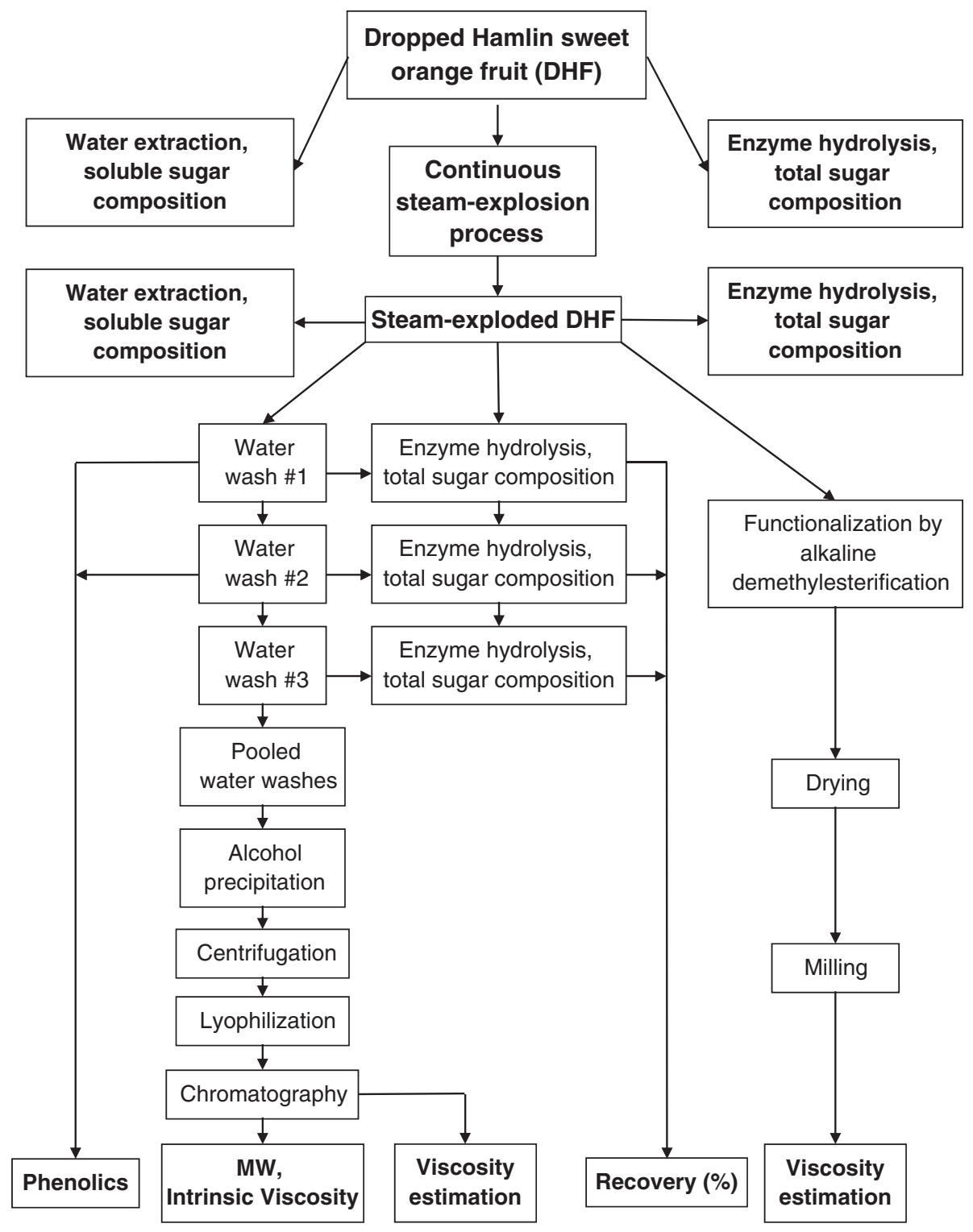

Figure 1. Schematic diagram of continuous, pilot-scale process for enhanced release and recovery of pectic hydrocolloids and phenolics from citrus dropped 'Hamlin' fruit and bench-scale functionalization of pectic hydrocolloids.

dialyzed overnight against multiple changes of deionized water (6000-8000 Da, molecular weight cut-off; Spectra/Por; Spectrum Laboratories Inc., Rancho Dominguez, CA, USA). The dialyzed samples were used for compositional and structural characterization. Following dialysis, the solution was precipitated and lyophilized as described above. Compositional analysis was performed on the precipitated, dialyzed pectin as described above.

Pectin from uncooked peel of dropped 'Hamlin' fruit was extracted using a hot, acid extraction method. Raw peel $(115 \mathrm{~g})$ was cut into small pieces and dropped into $500 \mathrm{~mL}$ of preheated $\left(70^{\circ} \mathrm{C}\right)$ deionized water and adjusted to $\mathrm{pH} 1.8$ using concentrated nitric acid. The slurry was maintained at $70^{\circ} \mathrm{C}$ and stirred for $3 \mathrm{~h}$. Next, the $\mathrm{pH}$ was adjusted to $\mathrm{pH} 2.2$ using $0.5 \mathrm{~mol} \mathrm{~L}^{-1}$ $\mathrm{NaOH}$ and allowed to cool to room temperature. The slurry was then filtered through a $1 \mathrm{~mm}$ metal filter and finally through two layers of cheesecloth. Pectin in the filtrate was precipitated using three volumes of isopropanol (IPA) and refrigerated overnight. The precipitate was pelleted by centrifugation at $21800 \times g$ for
$20 \mathrm{~min}$. The pellets were washed with IPA $\left(750 \mathrm{mLL}^{-1}\right)$ and then centrifuged as described above. The final pellets were lyophilized as described above.

\section{Demethylesterification of pectic hydrocolloids}

The steam-exploded dropped 'Hamlin' fruit was made into a slurry containing cooked fruit tissue $\left(150 \mathrm{~g} \mathrm{~L}^{-1}\right)$ in cold $\left(4^{\circ} \mathrm{C}\right)$ $0.05 \mathrm{~mol} \mathrm{~L}^{-1}$ trisodium phosphate (TSP) to obtain a pH of 12.0 for the alkaline demethylesterification of the released pectic hydrocolloids as described previously. ${ }^{30}$ Alternatively, the precipitated pectic hydrocolloids obtained from water washing of the steam-exploded dropped 'Hamlin' fruit were alkaline demethylesterified using sodium hydroxide as described previously. ${ }^{27}$

\section{Structural characterization of pectic hydrocolloids}

For estimation of the degree of methylesterification (DM) and acetylation (DA) the galacturonic acid content (GalA) was 
determined by a sulfamate/3-phenylphenol colorimetric method 31 as modified by Yoo et al. ${ }^{32}$ The DM and DA were determined by high-performance liquid chromatography (HPLC). ${ }^{33}$ Each sample was replicated three or four times.

Macromolecular properties of the dialyzed, lyophilized pectic hydrocolloids obtained from acid extraction of intact dropped 'Hamlin' fruit and water washes of the steam-exploded dropped 'Hamlin' fruit were prepared and chromatographed as described previously. ${ }^{34}$ Each sample was replicated three times.

\section{Functionality of pectic hydrocolloids}

Dried, milled TSP-treated steam-exploded dropped 'Hamlin' fruit was used to determine the viscosity associated with the alkaline demethylesterified pectic hydrocolloids contained within the tissue. Viscosity of alkaline demethylesterified pectin extracted from steam-exploded dropped 'Hamlin' fruit using a water wash also was determined. An AR 2000 Rheometer (TA Analytical, Wilmington, DE, USA) equipped with a stainless steel, $60 \mathrm{~mm}$ cone and plate geometry ( $2^{\circ}$ angle) was used for flow measurements of TSP-treated steam-exploded material along with controlled shear. TSP-treated steam-exploded dropped 'Hamlin' fruit slurries were prepared at either a concentration of 15 or $30 \mathrm{~g} \mathrm{~kg}^{-1}$ by adding 0.15 or $0.3 \mathrm{~g}$ of the dried, milled material to $10 \mathrm{~mL}$ of deionized water and stirred for $60 \mathrm{~min}$. Excess calcium ( $50 \mu \mathrm{L}$ aliquot of a $5 \mathrm{~mol} \mathrm{~L}^{-1}$ solution of $\left(\mathrm{CaCl}_{2}\right.$ ) was added to the steam-exploded dropped 'Hamlin' fruit suspension and a $5 \mathrm{~mL}$ pipette was used to mix the suspension by drawing the suspension up into the pipette tip three times. The suspension was placed on the geometry and the plate was lowered. Approximately 1 min was required to bring the temperature up to the set point of $80^{\circ} \mathrm{C}$. Following a 2 min equilibration and a $10 \mathrm{~min}$ time sweep (strain $=0.02$, frequency $=0.2 \mathrm{~Hz}$ ), a peak hold step was performed for $15 \mathrm{~min}$ at shear rate of $170 \mathrm{~L} \mathrm{~s}^{-1}$ with measurements taken every $30 \mathrm{~s}$.

Calcium-induced viscoelasticity in gels made with water extracted, alkaline demethylesterified pectic hydrocolloids or TSP-treated steam-exploded dropped 'Hamlin' fruit was measured under stress control using an acrylic parallel plate geometry. Solutions were made to $10 \mathrm{~g} \mathrm{~kg}^{-1}$ in deionized water, which was stirred for $24 \mathrm{~h}$. The pH was adjusted to 7.0 and $0.01 \mathrm{~g}$ of $\mathrm{CaH}_{2} \mathrm{PO}_{4}$ was added and mixed for $2 \mathrm{~h}$. No gel formation was observed during this time. Then the $\mathrm{pH}$ was slowly adjusted to 5.5 using glucono- $\delta$-lactone prompting the uniform release of calcium ions and allowing the gel to form in place. The gap was adjusted to $56 \mu \mathrm{m}$ and $4 \mathrm{~mL}$ of the sample was placed in the geometry and a manufacturer designed cover was used to prevent evaporation. The storage $\left(G^{\prime}\right)$ and loss moduli $\left(G^{\prime \prime}\right)$ were measured in the linear viscoelastic region at $20^{\circ} \mathrm{C}$ over a frequency range of $0.10-10.45 \mathrm{~Hz}$. The rheological measurements were performed in triplicate.

\section{Extraction and quantification of phenolic compounds}

Triplicate samples of lightly chopped dropped 'Hamlin' fruit or steam-exploded dropped 'Hamlin' fruit tissue ( $15 \mathrm{~g}$ wet weight) were homogenized in $250 \mathrm{~mL}$ of methanol with a Polytron homogenizer (Kinematica, Bohemia, NY, USA) at medium speed for $1 \mathrm{~min}$. The methanol extracts were vacuum filtered and the homogenization was repeated two additional times. The volumes of the combined methanol extracts were measured. From each extract, three $15 \mathrm{~mL}$ portions were evaporated to dryness at $45^{\circ} \mathrm{C}$ with a Savant centrifugal evaporator (Thermo Scientific, Waltham, MA, USA). Each sample was dissolved in $3.0 \mathrm{~mL}$ of dimethylsufoxide and was then analyzed by HPLC-electrospray ionization-mass spectrometry. ${ }^{35}$ Flavonoids and limonoids were analyzed as described previously. ${ }^{35}$ Identification of compounds was carried out by absorbance and mass spectrometry, as well as by comparison of the retention times of samples and authentic standards. ${ }^{36}$

\section{RESULTS AND DISCUSSION}

\section{Hydrocolloid composition of raw and steam-exploded fruit}

Total dry matter in the dropped 'Hamlin' fruit was $145.2 \mathrm{~g} \mathrm{~kg}^{-1}$. Following steam explosion, it was $124.8 \mathrm{~g} \mathrm{~kg}^{-1}$. Soluble sugar contents of raw, steam-exploded dropped 'Hamlin' fruit and water extracts are presented in Table 1. Except for minor amounts of galactose, only glucose, fructose and sucrose were detected in the water extracts of unhydrolyzed, raw or steam-exploded dropped 'Hamlin' fruit. Of the major sugars associated with pectic hydrocolloids (galacturonic acid, rhamnose, arabinose and galactose), only minor amounts of galactose were detected before enzymatic hydrolysis. These findings are in agreement with previous studies. ${ }^{26,27}$ Enzymatic hydrolysis resulted in an increase in glucose and fructose yields resulting from the hydrolysis of cellulose and sucrose. The concentrations of these non-pectic sugars are in agreement with values previously reported for 'Hamlin' orange peel. ${ }^{37}$ Amounts of glucose and fructose in dropped 'Hamlin' fruit were higher than previously measured for 'Hamlin' waste peel following juice extraction, although sucrose was lower. ${ }^{26}$ In hydrolyzed extracts, only arabinose and rhamnose concentrations were statistically different between raw and steam-exploded fruit tissue. However, the pectic sugars arabinose, galactose and GalA were much higher in hydrolyzed 'Hamlin' waste peel versus dropped 'Hamlin' fruit, whereas the differences for rhamnose and xylose were negligible. ${ }^{26}$ Similar results were mirrored in hydrolyzed steam-exploded samples. The dramatic reduction in GalA concentration in hydrolyzed dropped 'Hamlin' fruit or steam-exploded dropped 'Hamlin' fruit versus 'Hamlin' waste peel $(7.53 \pm 0.00 \%$ and $7.84 \pm 0.05 \%$ versus $13.00 \% \pm 0.02$, respectively) suggests real differences in the pectic hydrocolloid components between dropped fruit and fruit that matures on the tree. The comparable rhamnose concentrations $(0.80 \pm 0.015$ versus $0.73 \pm 0.00 \%$; dropped 'Hamlin' fruit versus 'Hamlin' waste peel, respectively) might suggest that the rhamnogalacturonan regions of pectin may remain similar and that the increase in arabinose and galactose are related to non-pectic arabinogalactans. Figure 2 shows the amount of pectic sugars extracted from the steam-exploded dropped 'Hamlin' fruit using three sequential water washes. Figure 3 indicates the recovery percentage in each wash for these pectic sugars. Approaching $90 \%$ of the GalA was recovered in the first wash. These recovery percentages are larger than that observed previously for citrus processing waste from either 'Hamlin' or 'Valencia' oranges. ${ }^{26,27}$

\section{Structural characterization of pectin hydrocolloids}

The DM for raw dropped 'Hamlin' fruit and steam-exploded dropped 'Hamlin' fruit was $46.9 \pm 2.08 \%$ and $62.3 \pm 1.27 \%$, respectively. The DM value for raw dropped 'Hamlin' fruit was lower than expected from pectin extracted from raw citrus peel, ${ }^{38}$ although the DM of the steam-exploded dropped 'Hamlin' fruit was close to values previously presented for steam-exploded fruit tissue. ${ }^{27}$ DA values were estimated at $5.5 \pm 0.13 \%$ and $3.0 \pm 0.07 \%$ from raw dropped 'Hamlin' fruit and steam-exploded dropped 'Hamlin' 


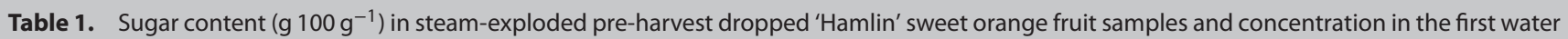
wash of steam-exploded pre-harvest dropped 'Hamlin' sweet orange fruit

\begin{tabular}{|c|c|c|c|c|c|c|c|c|}
\hline \multirow[b]{2}{*}{ Sample } & \multicolumn{8}{|c|}{ Sugar content by weight (mean \pm SE) } \\
\hline & Glucose & Fructose & Sucrose & Arabinose & Galactose & Rhamnose & Xylose & GalA \\
\hline $\begin{array}{l}\text { Raw } \\
\text { Soluble }\end{array}$ & $12.98 \pm 0.01 \ddagger \S$ & $13.60 \pm 0.05 \ddagger 9$ & $11.47 \pm 0.02+9$ & $0.00 \pm 0.00 \dagger 9$ & $0.17 \pm 0.00$ & $0.00 \pm 0.00 \dagger$ & $0.00 \pm 0.00 \dagger$ & $0.00 \pm 0.00^{*}$ \\
\hline $\begin{array}{l}\text { Raw } \\
\text { Hydrolyzed }\end{array}$ & $27.19 \pm 0.01$ & $17.86 \pm 0.07$ & $0.00 \pm 0.00$ & $3.29 \pm 0.019$ & $1.84 \pm 0.00$ & $0.70 \pm 0.019$ & $1.14 \pm 0.00$ & $7.53 \pm 0.00$ \\
\hline $\begin{array}{l}\text { Steam-exploded } \\
\text { Soluble }^{\text {a }}\end{array}$ & $15.78 \pm 0.10 \dagger$ & $15.91 \pm 0.03^{*}$ & $5.91 \pm 0.00^{*}$ & $0.00 \pm 0.00^{*}$ & $0.18 \pm 0.00$ & $0.00 \pm 0.00 \dagger$ & $0.00 \pm 0.00$ & $0.00 \pm 0.00 \dagger$ \\
\hline $\begin{array}{l}\text { Steam-exploded } \\
\text { Hydrolyzed }^{a}\end{array}$ & $27.83 \pm 0.22$ & $17.26 \pm 0.02$ & $0.00 \pm 0.00$ & $3.62 \pm 0.00$ & $1.91 \pm 0.07$ & $0.80 \pm 0.01$ & $1.02 \pm 0.12$ & $7.84 \pm 0.05$ \\
\hline $\begin{array}{l}\text { Steam-exploded } \\
\text { First water wash } \\
\text { Hydrolyzed }^{\mathrm{b}}\end{array}$ & $1.79 \pm 0.00$ & $1.21 \pm 0.01$ & 0.00 & $0.18 \pm 0.00$ & $0.10 \pm 0.00$ & $0.05 \pm 0.00$ & $0.01 \pm 0.00$ & $0.52 \pm 0.00$ \\
\hline
\end{tabular}

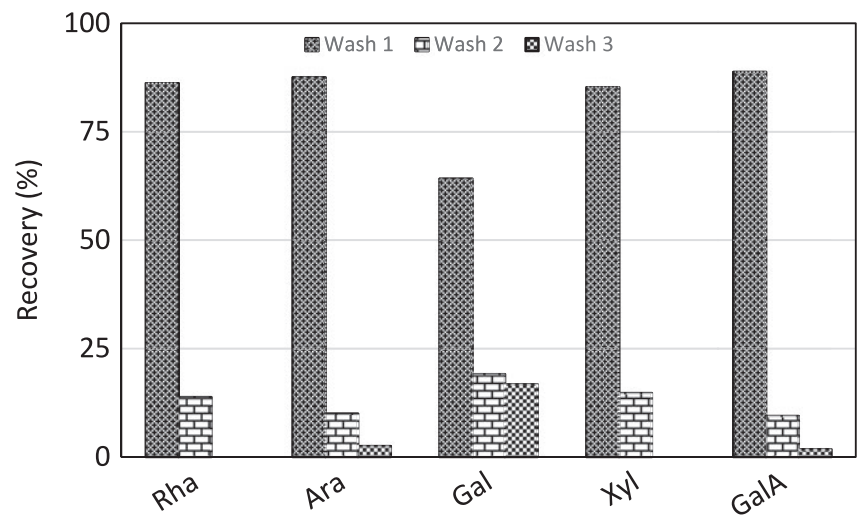

Figure 2. Recovery percentage of major pectic hydrocolloid sugars summed from three consecutive water washes of steam-exploded dropped 'Hamlin' fruit. Rha, rhamnose; Ara, arabinose; Gal, galactose; Xyl, xylose; GalA, galacturonic acid.

fruit, respectively. The DA values are in line with previous reports for citrus. ${ }^{33}$

Figures 4 and 5 illustrate representative size exclusion chromatograms for the dialyzed, acid extracted pectic hydrocolloids from raw dropped 'Hamlin' fruit and water extracted pectic hydrocolloids from steam-exploded dropped 'Hamlin' fruit, respectively. Bimodal distributions were observed in both samples. Extremely large aggregate macromolecules elute first, more so in steam-exploded dropped 'Hamlin' fruit (Table 2), although they comprise less than $1.0 \%$ of the samples. The raw dropped 'Hamlin' fruit chromatogram (Fig. 4) demonstrates more overlaps of all detector signals compared to steam-exploded dropped 'Hamlin' fruit (Fig.5), indicating that raw dropped 'Hamlin' fruit had an overall narrower molar mass distribution then steam-exploded dropped 'Hamlin' fruit, as shown in Table 2. The difference in polydispersity $\left(M_{\mathrm{w}} / M_{\mathrm{n}}\right)$ between two samples is $55 \%$. The conventional method of hot acid extraction used for raw dropped 'Hamlin' fruit pectic hydrocolloid retains higher $M_{w^{\prime}}\left[\eta_{w}\right]$ and $R g_{z}$ compared to steam-exploded dropped 'Hamlin' fruit. In both samples, subpopulations of pectic hydrocolloids can be identified

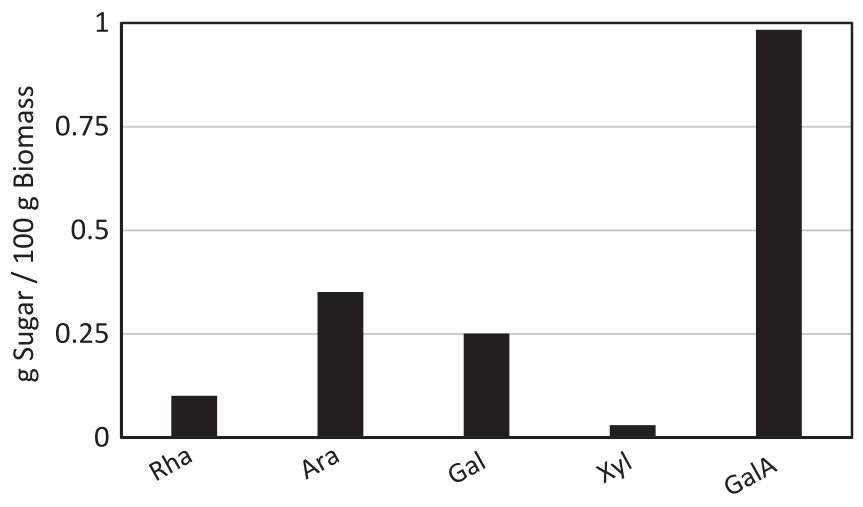

Figure 3. Mass of major pectic hydrocolloid sugars recovered from $100 \mathrm{~g}$ steam-exploded dropped 'Hamlin' fruit. Rha, rhamnose; Ara, arabinose; Gal, galactose; Xyl, xylose; GalA, galacturonic acid.

using the curve integration by part functions of the Astra software (Wyatt Technology, Santa Barbara, CA, USA) based on exponential fitting of the molar mass signal. ${ }^{39} A$ total of four subpopulations were identified in the acid extracted, raw dropped 'Hamlin' fruit pectic hydrocolloids and five in the steam-exploded dropped 'Hamlin' fruit extracted material. Inspecting the light scattering (LS) and differential refractive index (RI) traces on the chromatograms, it can be seen that a larger proportion of the steam-exploded dropped 'Hamlin' fruit material eluted later (after $35 \mathrm{~min}$ ) compared to the raw dropped 'Hamlin' fruit material. Based on the analysis of the distribution of molar mass, none of the raw dropped 'Hamlin' fruit subpopulation material had an $M_{\mathrm{w}}$ less than $500 \mathrm{kDa}$, whereas, $70 \%$ of the steam-exploded dropped 'Hamlin' fruit subpopulation material was less than $300 \mathrm{kDa}$. The LS trace for steam-exploded dropped 'Hamlin' fruit (Fig. 5) demonstrated that the sample forms aggregates for peaks 1 and 2, when combined, represent approximately $1.0 \%$ of the sample mass. Continue heating during the steam explosion process breaks down the aggregates into smaller components (peaks 3-5) (Fig. 5). These results are also reflected in the viscosity $\left[\eta_{\mathrm{w}}\right]$ and $M_{\mathrm{w}} / M_{\mathrm{n}}$ values estimated for each sample (Table 2 ). The $\left[\eta_{w}\right]$ value for the raw 
dropped 'Hamlin' fruit total chromatogram $\left(6.44 \mathrm{dL} \mathrm{g}^{-1}\right)$ is in accordance with previously established values for citrus pectin. ${ }^{39}$ By contrast, the steam-exploded dropped 'Hamlin' fruit $\left[\eta_{\mathrm{w}}\right]$ value was much lower $\left(1.00 \mathrm{dL} \mathrm{g}^{-1}\right)$ and very similar to the previously determined value $\left(0.99 \mathrm{dL} \mathrm{g}^{-1}\right)$ for pectic hydrocolloids from 'Hamlin' steam-exploded, juice-extracted waste peel. ${ }^{26}$ The $M_{\mathrm{w}} / M_{\mathrm{n}}$ for the steam-exploded dropped 'Hamlin' fruit sample was almost twice that observed for the dropped 'Hamlin' fruit sample (Table 2). Dividing the entire population of pectic material into subpopulations illustrates how different the two samples are. One of the most obvious differences is that almost $70 \%$ of the mass for the steam-exploded dropped 'Hamlin' fruit had an $M_{\mathrm{w}}$ of less than $300 \mathrm{kDa}$. Another striking difference is seen when comparing the $\left[\eta_{w}\right]$ of the subpopulations for the two samples. The lowest value observed for the raw dropped 'Hamlin' fruit was $2.53 \mathrm{dL} \mathrm{g}^{-1}$ for the lowest molecular weight fraction, whereas the largest value for one of the subpopulations of the steam-exploded dropped 'Hamlin' fruit was $1.80 \mathrm{dL} \mathrm{g}^{-1}$. Although $M_{\mathrm{w}}$ for the steam-exploded dropped 'Hamlin' fruit (Fig. 5) total chromatogram is within the range found for commercial pectins, this is only because very high $M_{\mathrm{w}}$ values were calculated for the first three eluting subpopulations, which represent only $6.1 \%$ of the sample mass. In the subpopulation with the lowest $M_{\mathrm{w}}$ or $M_{\mathrm{n}}$, the molecular weight was greater in the steam-exploded dropped 'Hamlin' fruit sample, although, in both samples, this subpopulation did account for approximately $70 \%$ of the total mass. The $\eta_{w}$ for all subpopulations was higher in the steam-exploded dropped 'Hamlin' fruit than the previously reported values for the 'Hamlin' steam-exploded, juice-extracted peel. ${ }^{26} \mathrm{~A}$ comparison of the results reported in the present study for raw dropped 'Hamlin' fruit and steam-exploded dropped 'Hamlin' fruit and for those previously reported from juice-extracted, steam-exploded 'Hamlin', waste peel indicates that fragmentation of the pectic hydrocolloids occurs during the steam-explosion process. ${ }^{26}$ Because MW is an important factor in determining pectic functionality, ${ }^{38}$ especially in food grade applications, alternative industrial applications targeting the modification of viscosity for drilling fluids, the cation capturing properties of waste water remediation projects or hydration control in products such as cement or paints may be more appropriate.

\section{Functionality of pectic hydrocolloids}

Calcium-mediated gels of the extracted, alkaline demethylesterified pectic hydrocolloids were prepared and their mechanical spectra were determined in a frequency range of $0.1-10.4 \mathrm{~Hz}$ at $25^{\circ} \mathrm{C}$ (Fig. 6). The mechanical response of the gelled material was explored by scanning the frequency and the gel was characterized. Typically, strong gels have $G^{\prime}$ values an order of magnitude or greater than $G^{\prime \prime}$, whereas, in weaker gels, the difference between modulus values is much smaller. The stronger the gel the more force is required for deformation. ${ }^{40}$ The spectra in Fig. 6 have the typical form of physically cross-linked biopolymer gels, where $G^{\prime}$ is an order of magnitude higher than $G^{\prime \prime}$ throughout the spectra with the addition of $10 \mathrm{~g} \mathrm{~kg}^{-1} \mathrm{CaPO}_{4}$ with little frequency-dependence of $G^{\prime}$ but small increases observed in $G^{\prime \prime}$ at higher frequencies. With the addition of only $5 \mathrm{~g} \mathrm{~kg}^{-1} \mathrm{CaPO}_{4}, G^{\prime}$ and $G^{\prime \prime}$ were slightly reduced and the gels did weaken slightly at the higher frequencies where the difference between $G^{\prime}$ and $G^{\prime \prime}$ decreased to a value less than an order of magnitude. Larger values for $G^{\prime}$ and $G^{\prime \prime}$ were observed with the undialyzed pectic hydrocolloids. The addition of $\mathrm{CaCl}$ to the in situ TSP-treated steam-exploded dropped 'Hamlin' fruit resulted in much lower $G^{\prime}$ and $G^{\prime \prime}$ values for both concentrations of TSP-treated material $\left(15\right.$ and $\left.30 \mathrm{~g} \mathrm{~kg}^{-1}\right)$. These samples

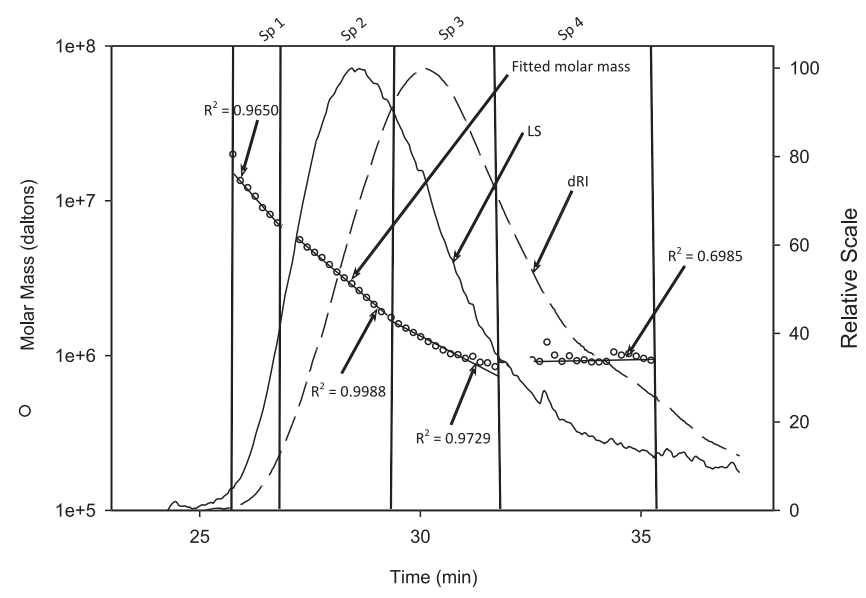

Figure 4. Size exclusion chromatography coupled to a multi angle laser light scattering detector of acid extracted, dialyzed, pectic hydrocolloids from raw dropped 'Hamlin' fruit with curve fitting as identified by four peaks within the chromatogram. Vertical lines are boundaries for integration by parts and fit-adjusted $r^{2}$ values are shown for each peak. Dotted trace indicates molar mass. Sp1, subpopulation 1; Sp2, subpopulation 2; $\mathrm{Sp} 3$, subpopulation 3; Sp4, subpopulation 4; LS, laser signal; dRI, differential refractive index.

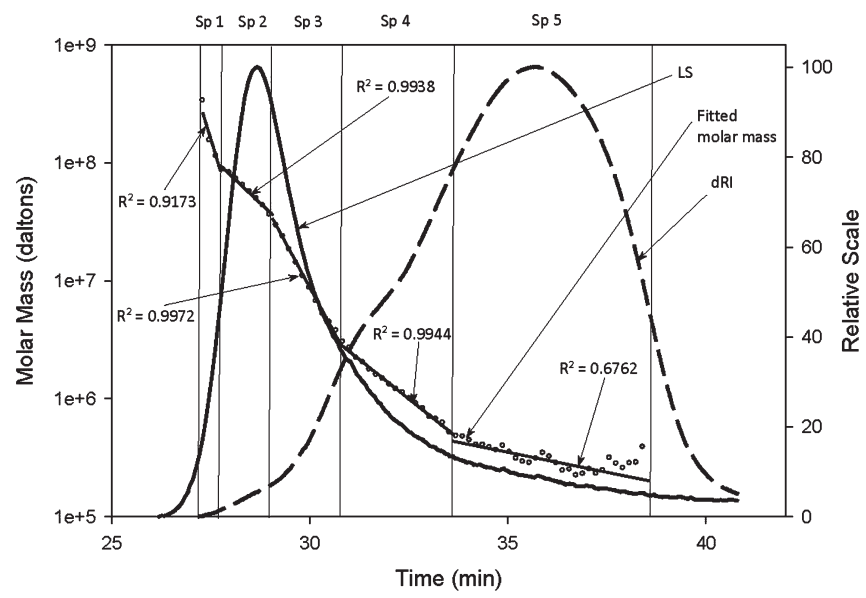

Figure 5. Size exclusion chomatography-multi-angle laser light scattering of water extracted pectic hydrocolloids from steam-exploded dropped 'Hamlin' fruit with curve fitting as identified by five peaks within the chromatogram. Vertical lines are boundaries for integration by parts and fit-adjusted $R^{2}$ values are shown for each peak. Dotted trace indicates molar mass. Sp1, subpopulation 1; Sp2, subpopulation 2; Sp3, subpopulation 3; Sp4, subpopulation 4; Sp5, subpopulation 5; LS, laser signal; dRI, differential refractive index.

produced very weak gels, with $G^{\prime}$ being less than an order of magnitude larger than $G^{\prime \prime}$.

Measured viscosities (Fig.7) were also much higher for the alkaline demethylesterified pectic hydrocolloids versus the in situ TSP-treated material. Very minor differences were observed for the dialyzed versus undialyzed material and $10 \mathrm{~mL} \mathrm{~L}^{-1}$ solutions were more than two-fold higher than the $5 \mathrm{~mL} \mathrm{~L}^{-1}$ solutions throughout the measurement period. TSP-treated material produced very low viscosity throughout the runs.

\section{Flavonoid and limonoid composition of raw and steam-exploded dropped fruit}

The content of many of the flavonoids, particularly the polymethoxylated flavones, in the 'Hamlin' dropped fruit, measured 
Table 2. Macromolecular properties of recovered pectic hydrocolloids estimated by size exclusion chromatography coupled to a multi-angle laser light scattering photometer, differential pressure viscometer and a differential refractive index detector for the total eluted mass and individual subpopulations (Sp) of water extracted pectic hydrocolloids identified in each sample

\begin{tabular}{|lccccccc} 
& \multicolumn{7}{c}{ Parameter (mean $\pm \mathrm{SD})$} \\
\cline { 2 - 7 } Sample & Peak \# & Mass (\%) & $M_{\mathrm{w}}(\mathrm{Da})$ & $M_{\mathrm{n}}(\mathrm{Da})$ & $M_{\mathrm{w}} / M_{\mathrm{n}}$ & $R g_{\mathrm{z}}(\mathrm{nm})$ & $\left.\eta_{\mathrm{w}}(\mathrm{dL} \mathrm{g})^{-1}\right)$ \\
\hline Dropped 'Hamlin' & $\mathrm{TC}$ & $100(0.0)$ & $1.25 \times 10^{6}\left(5.79 \times 10^{4}\right)$ & $5.62 \times 10^{5}\left(5.79 \times 10^{4}\right)$ & $2.35(0.25)$ & $58.6(2.4)$ & $6.44(0.05)$ \\
sweet orange fruit & $\mathrm{Sp} 1$ & $0.93(0.32)$ & $7.82 \times 10^{6}\left(6.24 \times 10^{5}\right)$ & $7.46 \times 10^{6}\left(5.94 \times 10^{5}\right)$ & $1.03(0.02)$ & $85.7(4.1)$ & $18.14(1.80)$ \\
& $\mathrm{Sp} 2$ & $21.4(2.42)$ & $2.99 \times 10^{6}\left(1.63 \times 10^{5}\right)$ & $2.71 \times 10^{6}\left(1.13 \times 10^{5}\right)$ & $1.10(0.02)$ & $63.4(1.0)$ & $11.32(0.18)$ \\
& $\mathrm{Sp3}$ & $45.3(0.61)$ & $1.09 \times 10^{6}\left(7.07 \times 10^{4}\right)$ & $1.01 \times 10^{6}\left(8.63 \times 10^{4}\right)$ & $1.08(0.02)$ & $49.5(2.4)$ & $6.75(0.35)$ \\
& $\mathrm{Sp} 4$ & $32.4(2.08)$ & $5.17 \times 10^{5}\left(4.37 \times 10^{5}\right)$ & $6.78 \times 10^{4}\left(2.12 \times 10^{5}\right)$ & $1.00(0.00)$ & - & $2.53(0.28)$ \\
Steam-Exploded Dropped & $\mathrm{TC}$ & $100(0.0)$ & $1.40 \times 10^{6}\left(2.55 \times 10^{4}\right)$ & $3.62 \times 10^{5}\left(1.43 \times 10^{4}\right)$ & $4.28(0.11)$ & $43.5(8.2)$ & $1.00(0.02)$ \\
'Hamlin' sweet orange & $\mathrm{Sp}$ & $0.1(0.1)$ & $1.30 \times 10^{8}\left(3.93 \times 10^{7}\right)$ & $1.221 \times 10^{8}\left(3.19 \times 10^{7}\right)$ & $1.07(0.05)$ & $54.9(10.7)$ & $1.31(0.50)$ \\
fruit & $\mathrm{Sp} 2$ & $0.9(0.1)$ & $5.47 \times 10^{7}\left(4.00 \times 10^{6}\right)$ & $5.09 \times 10^{7}\left(4.00 \times 10^{6}\right)$ & $1.07(0.03)$ & $50.0(0.8)$ & $1.02(0.11)$ \\
& $\mathrm{Sp3}$ & $5.1(0.1)$ & $8.69 \times 10^{6}\left(2.97 \times 10^{5}\right)$ & $5.40 \times 10^{6}\left(3.07 \times 10^{5}\right)$ & $1.57(0.00)$ & - & $1.72(0.03)$ \\
& $\mathrm{Sp4}$ & $24.1(0.1)$ & $1.16 \times 10^{6}\left(4.25 \times 10^{4}\right)$ & $9.19 \times 10^{5}\left(3.43 \times 10^{4}\right)$ & $1.27(0.01)$ & - & $1.80(0.02)$ \\
& $\mathrm{Sp} 5$ & $69.9(0.2)$ & $2.92 \times 10^{5}\left(1.94 \times 10^{4}\right)$ & $2.81 \times 10^{5}\left(1.71 \times 10^{4}\right)$ & $1.04(0.01)$ & - & $0.67(0.02)$
\end{tabular}

Mass, percentage of recovered mass contained within the sub-population; $M_{\mathrm{w}}$, weight average molecular weight; $M_{\mathrm{n}}$, number average molecular weight; $R g_{z}$, root mean square radius of gyration; $\eta_{\mathrm{W}}$, intrinsic viscosity; TC, total chromatogram (total eluted mass). The mean $\pm \mathrm{SD}$ are based on three replicates.

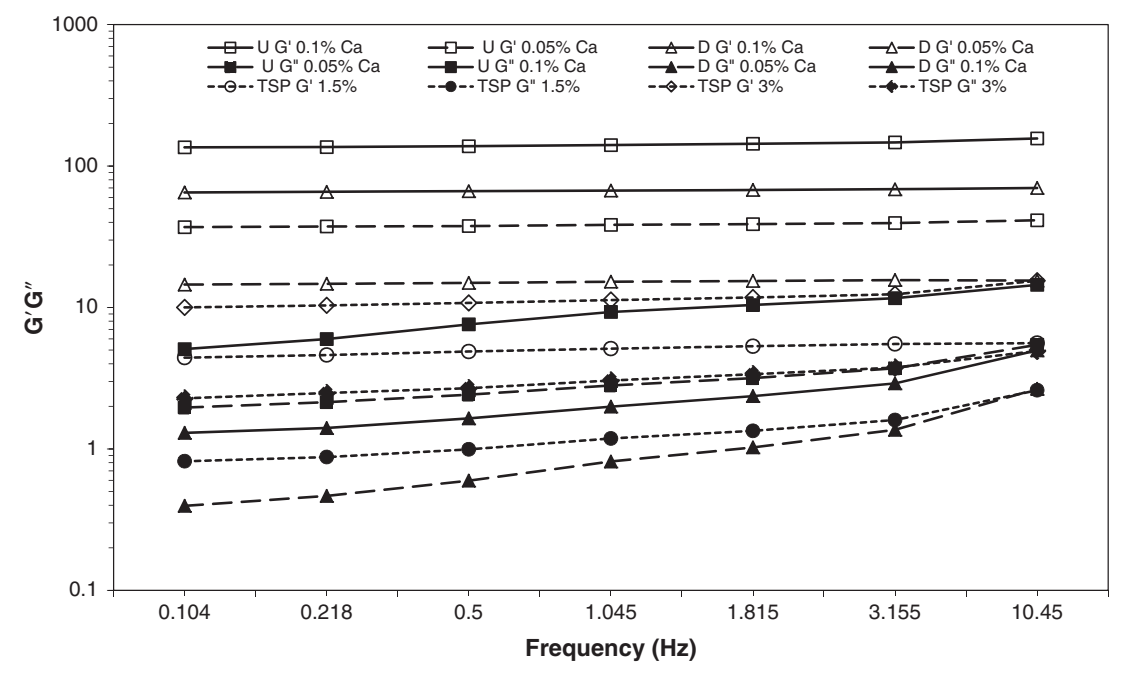

Figure 6. Mechanical spectrum ( $1 \%$ strain) recorded for 5 and $10 \mathrm{~g} \mathrm{~kg}^{-1}$ dialyzed and undialyzed alkaline demethylesterified pectic hydrocolloids from water washed steam-exploded dropped 'Hamlin' fruit or 15 and $30 \mathrm{~g} \mathrm{~kg}^{-1}$ alkaline demethylesterified steam-exploded dropped 'Hamlin' fruit in the presence of $1 \mathrm{~g} \mathrm{~kg}^{-1} \mathrm{CaPO}_{4}$ at $20^{\circ} \mathrm{C}$.

as ppm dry weight (Table 3), closely matched the values reported earlier for raw 'Hamlin' peel, ${ }^{26}$ whereas the total concentrations of the flavanone glycosides, especially hesperidin, were substantially higher for the fruit reported in Table 3 ( $55 \mathrm{~g} \mathrm{~kg}^{-1}$ dry weight) than the earlier reported value of $33 \mathrm{~g} \mathrm{~kg}^{-1}$ dry weight. As expected, the limonoid aglycone (nomilin and limonin) amounts in the whole fruit (Table 3 ) were only approximately half the values measured in chopped peel.

As shown in Table 3, the water washes of the steam-exploded dropped 'Hamlin' fruit produced from 1000 boxes of dropped 'Hamlin' fruit contained very similar levels of flavonoid and limonoids compared to the levels reported for 'Valencia' peel, with the major exception of hesperidin. The water wash produced from the steam explosion of 1000 boxes of dropped 'Hamlin' fruit recovered $349 \mathrm{~kg}$ of hesperidin, whereas the earlier experiment with 'Valencia' peel recovered only $14 \mathrm{~kg}$ per 1000 boxes. We propose that the juice contained in the dropped 'Hamlin' fruit may have enhanced the extraction and solubility of the whole fruit hesperidin compared to hot water peel extraction. In a similar manner, we found enhanced extraction and recovery of the dropped 'Hamlin' fruit limonoid aglycones and glucosides compared to isolated peel. The almost complete recovery of the limonoids in the water washes of the steam-exploded dropped 'Hamlin' fruit contrast sharply with similar work with isolated orange fruit peels. Recovery of the total polymethoxylated flavones in the water washes of the steam-exploded dropped 'Hamlin' fruit (Table 3) occurred at 38\%, and is similar to findings made with isolated peel. Hydroxycinnamate recoveries were above $80 \%$ (data not shown) and this is in agreement with earlier steam explosion of orange fruit peel.

The results relating to the quantitation of the dropped 'Hamlin' fruit flavonoids and limonoids demonstrate that the steam explosion process produces readily extractable compounds at high percentage recoveries. The evidence provided in Table 3 suggests that the steam-exploded dropped 'Hamlin' fruit might be a better 


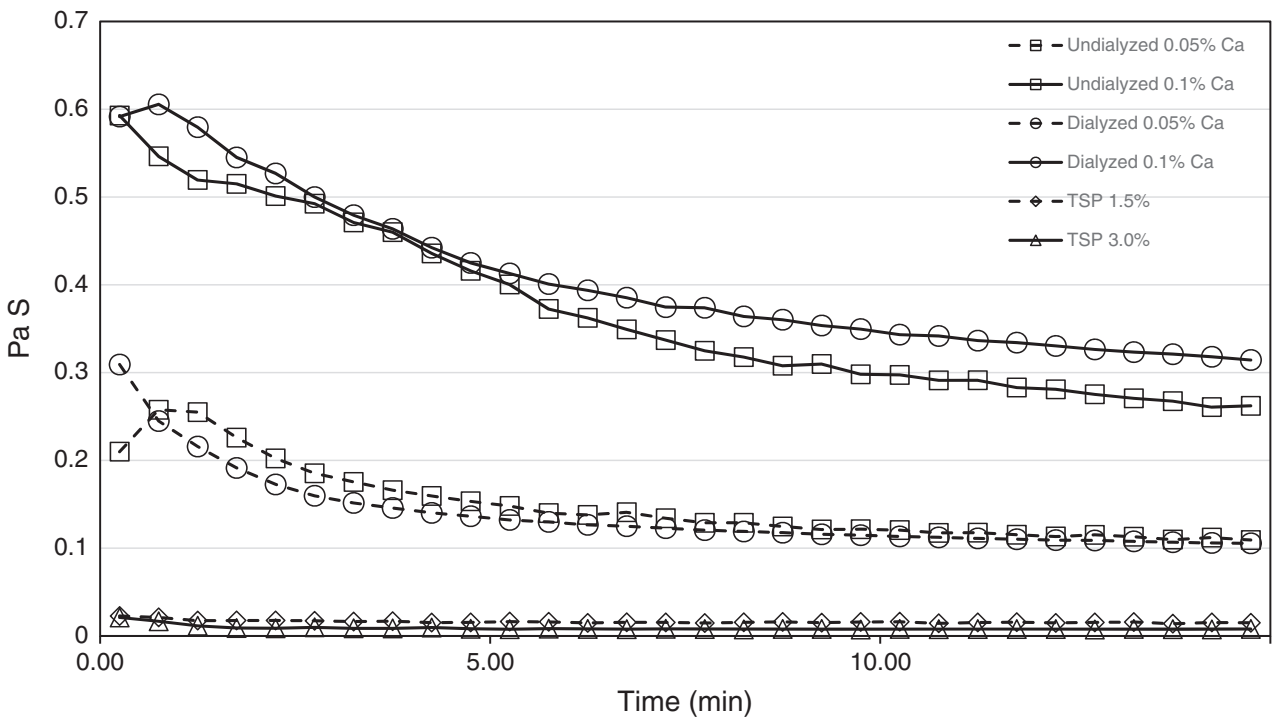

Figure 7. Calcium induced viscosity of 5 and $10 \mathrm{~g} \mathrm{~kg}^{-1}$ dialyzed and undialyzed alkaline demethylesterified pectic hydrocolloids from water washed steam-exploded dropped 'Hamlin' fruit or 15 and $30 \mathrm{~g} \mathrm{~kg}^{-1}$ suspensions of dried, milled steam-exploded dropped 'Hamlin' fruit.

Table 3. Concentrations and amounts of phenolics and limonoids in raw pre-harvest dropped 'Hamlin' sweet orange fruit and first two combined water washes of steam-exploded pre-harvest dropped 'Hamlin' sweet orange fruit in the 2013-14 season

\begin{tabular}{|c|c|c|c|c|c|}
\hline Compound & $\begin{array}{c}\text { Parts per million } \\
\text { in raw fruit (mean } \pm S E)\end{array}$ & $\begin{array}{l}\mathrm{kg} / 1000 \text { boxes in raw } \\
\text { fruit }(\text { mean } \pm \mathrm{SE})\end{array}$ & $\begin{array}{l}\mathrm{kg} / 1000 \text { boxes in water } \\
\text { wash of steam-exploded } \\
\text { fruit (mean } \pm \mathrm{SE} \text { ) }\end{array}$ & $\begin{array}{l}\text { Total tonnes } \\
\text { in raw fruit } \\
\text { (mean } \pm S E \text { ) }\end{array}$ & $\begin{array}{c}\text { Total } \\
\text { tonnes in water } \\
\text { wash of steam-explod } \\
\text { fruit (mean } \pm \mathrm{SE} \text {; percent } \\
\text { recovery versus raw fru }\end{array}$ \\
\hline \multicolumn{6}{|c|}{ Flavanone glycosides } \\
\hline NR4G & $1217.9 \pm 56.1$ & $6.2 \pm 0.3$ & $4.7 \pm 0.7$ & $55.8 \pm 2.6$ & $41.9 \pm 1.0(75.1 \%)$ \\
\hline HSPG & $969.5 \pm 24.0$ & $4.9 \pm 0.2$ & $3.0 \pm 0.1$ & $44.4 \pm 1.1$ & $27.3 \pm 0.8(61.5 \%)$ \\
\hline $\mathrm{NR}$ & $5096.1 \pm 96.1$ & $25.9 \pm 0.5$ & $12.7 \pm 0.03$ & $233.4 \pm 4.4$ & $114.2 \pm 0.3(48.9 \%)$ \\
\hline HSP & $44375 \pm 921.4$ & $225.8 \pm 4.7$ & $349.2 \pm 2.3$ & $2031.1 \pm 42.2$ & $3144 \pm 1.0(>100 \%)$ \\
\hline ISR & $3381.4 \pm 88.1$ & $17.2 \pm 0.4$ & $3.3 \pm 0.02$ & $154.8 \pm 4.0$ & $30.2 \pm 0.2(19.5 \%)$ \\
\hline \multicolumn{6}{|c|}{ Polymethoxylated flavones } \\
\hline ISOSIN & $80.1 \pm 5.6$ & $0.4 \pm 0.03$ & $0.09 \pm 0.01$ & $3.7 \pm 0.3$ & $0.8 \pm 0.1(21.6 \%)$ \\
\hline $\mathrm{SIN}$ & $176.2 \pm 9.6$ & $0.9 \pm 0.05$ & $0.4 \pm 0.01$ & $8.1 \pm 0.4$ & $3.9 \pm 0.1(48.1 \%)$ \\
\hline QHME & $16.0 \pm 0.8$ & $0.08 \pm 0.01$ & $0.04 \pm 0.01$ & $0.7 \pm 0.0$ & $0.4 \pm 0.0(57.1 \%)$ \\
\hline NOB & $360.5 \pm 17.6$ & $1.8 \pm 0.09$ & $0.8 \pm 0.04$ & $16.5 \pm 0.8$ & $6.8 \pm 0.3(41.2 \%)$ \\
\hline TMS & $144.2 \pm 4.0$ & $0.7 \pm 0.02$ & $0.2 \pm 0.01$ & $6.6 \pm 0.2$ & $1.7 \pm 0.1(25.7 \%)$ \\
\hline HMF & $88.1 \pm 2.4$ & $0.4 \pm 0.01$ & $0.2 \pm 0.01$ & $4.0 \pm 0.1$ & $1.8 \pm 0.1(45.0 \%)$ \\
\hline DMS & $16.0 \pm 0$ & $0.08 \pm 0.0$ & $0.03 \pm 0.01$ & $0.7 \pm 0.1$ & $0.3 \pm 0.0(42.9 \%)$ \\
\hline TAN & $56.1 \pm 1.6$ & $0.3 \pm 0.01$ & $0.07 \pm 0.01$ & $2.6 \pm 0.1$ & $0.6 \pm 0.1(30.8 \%)$ \\
\hline DMN & $16.1 \pm 2.8$ & $0.08 \pm 0.01$ & $0.02 \pm 0.00$ & $0.7 \pm 0.1$ & $0.2 \pm 0.0(28.6 \%)$ \\
\hline \multicolumn{6}{|l|}{ Limonoids } \\
\hline LG & $1274 \pm 961$ & $6.5 \pm 0.9$ & $10.2 \pm 1.0$ & $58.3 \pm 8.4$ & $91.7 \pm 9.8(>100 \%)$ \\
\hline NAG & $857.3 \pm 160.2$ & $4.3 \pm 0.8$ & $6.1 \pm 0.9$ & $39.3 \pm 7.3$ & $54.7 \pm 7.8(>100 \%)$ \\
\hline NG & $961.5 \pm 112.1$ & $4.9 \pm 0.6$ & $6.9 \pm 0.8$ & $44.0 \pm 5.1$ & $62.5 \pm 6.9(>100 \%)$ \\
\hline NOM & $72.1 \pm 8.0$ & $0.4 \pm 0.04$ & $0.5 \pm 0.1$ & $3.3 \pm 0.4$ & $4.9 \pm 1.0(>100 \%)$ \\
\hline LIM & $448.7 \pm 24.0$ & $2.3 \pm 0.1$ & $3.4 \pm 0.4$ & $20.5 \pm 1.1$ & $30.3 \pm 3.9(>100 \%)$ \\
\hline
\end{tabular}

ISOSIN, isosinensetin; SIN, sinensetin; QHME, quercetagetin hexamethylether; NOB, nobiletin; TMS, tetramethylscutellarein; HMF, heptamethoxyflavone; DMS, 5-demethylsinensetin; TAN, tangeretin; DMN, 5-demethylnobiletin; DMTMS, 5-demethyltetramethylscutellarein; DMHMF, 5-demethylheptamethoxyflavone; NR4G, narirutin-4'-glucoside; HSPG, hesperidin-glucoside; NR, narirutin; HSP, hesperidin; ISR, isosakuranetin rutinoside; HSPTN, hesperetin; LG, limonin glucoside; L, limonin; NG, nomilin glucoside; N, nomilin; NAG, nomilinic acid glucoside. 
source of targeted flavonoids and limonoids than processed peel waste, and hence the dropped fruit caused by the HLB epidemic has value in terms of these potential health-based value-added compounds. The results with the pectic hydrocolloid recoveries further support this observation, in that the amount recoverable would provide a valuable and viable alternative to other hydrocolloids widely used for modifying the rheological properties of industrial fluids, such as drilling muds, ion capture agents in waste water remediation projects and hydration control agents found in paints and cement.

\section{ACKNOWLEDGEMNTS}

We thank Sandra Matlack, Peiling Li, Elena Branca, Veronica Cook and Andre White for their expert laboratory and pilot plant assistance.

\section{REFERENCES}

1 Albrigo LG and Stover EW, Effect of plant growth regulators and fungicides on huanglongbing-related preharvest fruit drop of citrus. Hort Technol 25:785-790 (2015).

2 Zhao W, Bai J, McCollum G and Baldwin E, High incidence of preharvest colonization of Huanglongbing-symptomatic Citrus sinensis fruit by Lasiodiplodia theobromae (Diplodia natalensis) and exacerbation of postharvest fruit decay by that fungus. Appl Environ Microbiol 81:364-372 (2015)

3 USDA, NASS, Citrus Fruit Size and Drop 2014-2015 Report (2015). [Online]. Available: https://www.nass.usda.gov/Statistics_by_State/ Florida/Publications/Citrus/Miscellaneous/Fruit\%20Size\%20and \%20Drop\%202016.pdf [2 November 2016].

4 Grohmann K, Cameron RG and Buslig BS, Fermentation of sugars in orange peel hydrolysates to ethanol by recombinant Escherichia coli KO11. Appl Biochem Biotechnol 51-52:423-435 (1995).

5 Grohmann K, Cameron RG and Buslig BS, Fractionation and pretreatment of orange peel by dilute acid hydrolysis. Bioresource Technol 54:129-141 (1995).

6 Wilkins MR, Widmer WW and Grohmann K, Simultaneous saccharification and fermentation of citrus peel waste by Saccharomyces cerevisiae to produce ethanol. Process Biochem 42:1614-1619 (2007).

7 Wilkins MR, Widmer WW, Grohmann K and Cameron RG, Hydrolysis of grapefruit peel waste with cellulase and pectinase enzymes. Bioresource Technol 98:1596-1601 (2007).

8 Stewart D, Widmer W, Grohman K and Wilkins M, Ethanol production from solid citrus waste. US Patent: 8372614 (2013).

9 Cameron RG, Kim Y, Galant AL, Luzio GA and Tzen JTC, Pectin homogalacturonans: Nanostructural characterization of methylesterified domains. Food Hydrocolloids 47:184-190 (2015).

10 Cameron RG, Luzio GA, Vasu P, Savary BJ and Williams MAK, Enzymatic modification of a model homogalacturonan with the thermally tolerant pectin methylesterase from Citrus: 1. Nanostructural characterization, enzyme mode of action, and effect of $\mathrm{pH}$. J Agric Food Chem 59:2717-2724 (2011)

11 Atmodjo MA, Hao Z and Mohnen D, Evolving views of pectin biosynthesis. Annu Rev Plant Biol 64:747-779 (2013).

12 Christiaens S, Van Buggenhout S, Houben K, Kermani ZJ, Moelants KRN, Ngouémazong ED et al., Process-structure-function relations of pectin in food. Crit Rev Food Sci 56:1021 - 1042 (2015).

13 Staunstrup J, Citrus pectin production and world market. [Online]. Available: http://www.conference.ifas.ufl.edu/citrus09/htms09/ pdfs/Thursday/0905\%20Staunstrup.pdf [8 November 2016].

14 Munarin F, Tanzi MC and Petrini P, Advances in biomedical applications of pectin gels. Int J Biol Macromolec 51:681-689 (2012).

15 Morris VJ, Belshaw NJ, Waldron KW and Maxwell EG, The bioactivity of modified pectin fragments. Bioact Carbohydr Diet Fibre 1:21-37 (2013).

16 Bredsdorff L, Nielsen ELF, Rasmussen SE, Cornett C, Barron D, Bouisset $F$ et al., Absorption, conjugation and excretion of the flavanones, naringenin and hesperetin from $\alpha$-rhamnosidase-treated orange juice in human subjects. Br J Nutr 103:1602-1609 (2010).

17 Brett GM, Hollands W, Needs PW, Teucher B, Dainty JR, Davis BD et al. Absorption, metabolism and excretion of flavanones from single portions of orange fruit and juice and effects of anthropometric variables and contraceptive pill use on flavanone excretion. Br J Nutr 101:664-675 (2009).

18 Vallejo F, Larrosa M, Escudero E, Zafrilla MP, Cerda B, Boza J et al., Concentration and solubility of flavanones in orange beverages affect their bioavailability in humans. J Agric Food Chem 58:6516-6524 (2010).

19 Murakami A, Song M, Katsumata SI, Uehara M, Suzuki K and Ohigashi $\mathrm{H}$, Citrus nobiletin suppresses bone loss in ovariectomized ddY mice and collagen-induced osteoclastogenesis regulation. BioFactors 30:179-192 (2007).

20 Onozuka H, Nakajima A, Matsuzaki K, Shin RW, Ogino K, Saigusa D et al., Nobiletin, a citrus flavonoids, improves memory impairment and $A B$ pathology in a transgenic mouse model of Alzheimer's disease. $J$ Pharm Exp Ther 326:739-744 (2008).

21 Yamakuni T, Nakajima A and Ohizumi Y, Preventive action of nobiletin, a constituent of Aurantii Nobilis Pericarpium with anti-dementia activity, against amyloid-beta peptide-induced neurotoxicity expression and memory impairment. Yakuga Zasshi 130:517-520 (2010).

22 USDA, NASS, Citrus World Trade and Markets (2014). [Online]. Available: http://www.fas.usda.gov/psdonline/psdHome.aspx [2 March 2016].

23 Marín FR, Soler-Rivas C, Benavente-García O, Castillo J and Pérez-Alvarez JA, By-products from different citrus processes as a source of customized functional fibres. Food Chem 100:736-741 (2007).

24 Citrus FDO, Annual Processor's Statistical Report 2013-2014 (2014). [Online]. Available: https://fdocgrower.app.box.com/shared/ h3tz6uz045/1/76180930 [2 April 2016].

25 Braddock RJ, Handbook of Citrus By-Products and Processing Technology. John Wiley \& Sons, Inc, New York, NY (1999).

26 Cameron RG, Chau HK and Manthey JA, Continuous process for enhanced release and recovery of pectic hydrocolloids and phenolics from citrus biomass. J Chem Technol Biotechnol 10:2597-2606 (2016).

27 Grohmann K, Cameron R, Kim Y, Widmer W and Luzio G, Extraction and recovery of pectic fragments from citrus processing waste for co-production with ethanol. J Chem Technol Biotechnol 88:395-407 (2013).

28 Widmer W, Zhou W and Grohmann K, Pretreatment effects on orange processing waste for making ethanol by simultaneous saccharification and fermentation. Bioresour Technol 101:5242-5249 (2010).

29 Kertesz ZI, The Pectic Substances, 1st edn. Interscience Publishers, New York, NY (1951).

30 Luzio GA, Cameron RG, Galant AL and Kauffman SW, Processes to produce unpurified polygalacturonic acid from plant tissue using calcium sequestering compounds. US Patent: 62050345 (2014).

31 Filisetti-Cozzi TMCC and Carpita NC, Measurement of uronic acids without interference from neutral sugars. Anal Biochem 197:157-162 (1991).

32 Yoo SH, Fishman ML, Savary BJ and Hotchkiss AT Jr, Monovalent salt-induced gelation of enzymatically deesterified pectin. J Agric Food Chem 51:7410-7417 (2003).

33 Voragen AGJ, Schols HA and Pilnik W, Determination of the degree of methylation and acetylation of pectins by HPLC. Food Hydrocolloids 1:65-70 (1986).

34 Fishman ML, Chau HK, Qi PX, Hotchkiss AT, Garcia RA and Cooke PH, Characterization of the global structure of low methoxyl pectin in solution. Food Hydrocolloids 46:153-159 (2015).

35 Hijaz FM, Manthey JA, Folimonova SY, Davis CL, Jones SE and Reyes-De-Corcuera Jl, An HPLC-MS characterization of the changes in sweet orange leaf metabolite profile following infection by the bacterial pathogen Candidatus Liberibacter asiaticus. PLOS ONE 8:e79485 (2013).

36 Bai J, Baldwin EA, McCollum G, Plotto A, Manthey JA, Widmer WW et al., Changes in volatile and non-volatile flavor chemicals of 'Valencia' orange juice over the harvest seasons. Foods 5:4 (2016).

37 Ting SV and Deszyck EJ, The carbohydrates in the peel of oranges and grapefruit. J Food Sci 26:146-152 (1961).

38 Rolin C, Commercial pectin preparations, in Pectins and their Manipulation, ed. by Seymour G and Knox JP. Blackwell Publishing Ltd, Oxford, pp. 222-241 (2002).

39 Fishman ML, Walker PN, Chau HK and Hotchkiss AT, Flash extraction of pectin from orange albedo by steam injection. Biomacromolecules 4:880-889 (2003).

40 Ross-Murphy SB and Shatwell KP, Polysaccharide strong and weak gels. Biorheology 30:217-227 (1993). 